\title{
Permanent diabetes during the first year of life: multiple gene screening in 54 patients
}

\author{
L. Russo • D. Iafusco $\cdot$ S. Brescianini $\cdot$ V. Nocerino $~ C$ C. Bizzarri $~ \cdot$ \\ S. Toni $\cdot$ F. Cerutti $\cdot$ C. Monciotti $\cdot$ R. Pesavento $\cdot$ L. Iughetti $\cdot$ \\ L. Bernardini • R. Bonfanti • L. Gargantini • M. Vanelli • \\ L. Aguilar-Bryan • M. A. Stazi • V. Grasso • C. Colombo • \\ F. Barbetti • the ISPED Early Diabetes Study Group
}

Received: 24 September 2010 / Accepted: 25 January 2011 /Published online: 10 March 2011

(C) The Author(s) 2011. This article is published with open access at Springerlink.com

\begin{abstract}
Aims/hypothesis The aim of this study was to investigate the genetic aetiology of permanent diabetes mellitus with onset in the first 12 months of age.

Methods We studied 46 probands with permanent, insulinrequiring diabetes with onset within the first 6 months of life (permanent neonatal diabetes mellitus [PNDM]/ monogenic diabetes of infancy [MDI]) (group 1) and eight participants with diabetes diagnosed between 7 and 12 months of age (group 2). KCNJ11, INS and ABCC8 genes were sequentially sequenced in all patients. For those
\end{abstract}

Electronic supplementary material The online version of this article (doi:10.1007/s00125-011-2094-8) contains supplementary material, which is available to authorised users.

L. Russo $\cdot$ V. Nocerino $\cdot$ C. Colombo $\cdot$ F. Barbetti

Laboratory of Mendelian Diabetes,

Ospedale Pediatrico Bambino Gesù,

IRCCS, Rome, Italy

D. Iafusco

Department of Pediatrics, Second University of Naples,

Naples, Italy

S. Brescianini $\cdot$ M. A. Stazi

Department of Epidemiology, Istituto Superiore di Sanità,

Rome, Italy

C. Bizzarri

Endocrinology Unit, Ospedale Pediatrico Bambino Gesù,

IRCCS, Rome, Italy

\section{S. Toni}

Regional Center for Juvenile Diabetes, Meyer Pediatric Hospital,

Florence, Italy

F. Cerutti

Department of Pediatrics, University of Turin,

Turin, Italy who were negative in the initial screening, we examined ERN1, CHGA, CHGB and NKX6-1 genes and, in selected probands, CACNA1C, GCK, FOXP3, NEUROG3 and $C D K 4$. The incidence rate for PNDM/MDI was calculated using a database of Italian patients collected from 1995 to 2009.

Results In group 1 we found mutations in KCNJ11, INS and $A B C C 8$ genes in $23(50 \%), 9(19.5 \%)$ and $4(8.6 \%)$ patients respectively, and a single homozygous mutation in $G C K$ $(2.1 \%)$. In group 2, we identified one incidence of a KCNJ11 mutation. No genetic defects were detected in

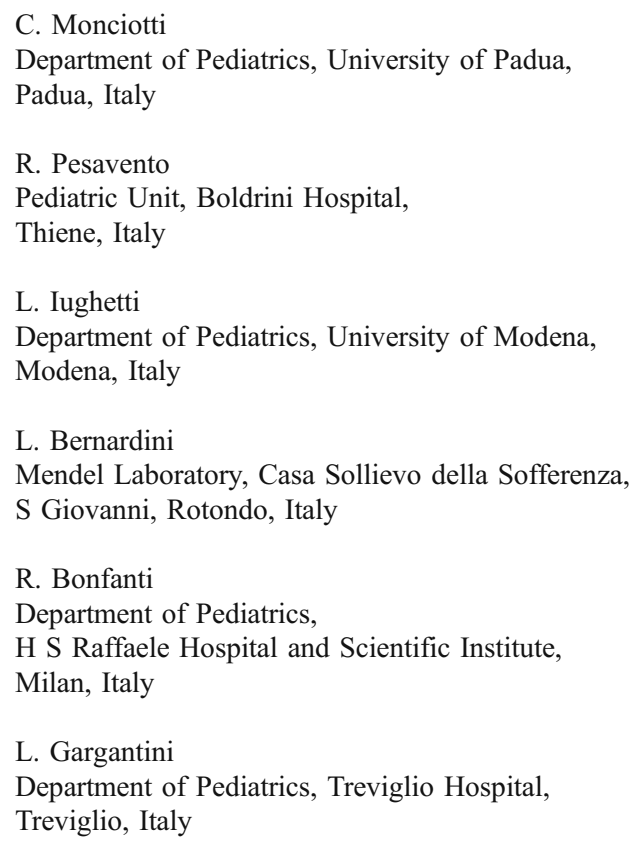


other loci. The incidence rate of PNDM/MDI in Italy is estimated to be 1:210,287.

Conclusions/interpretation Genetic mutations were identified in $\sim 75 \%$ of non-consanguineous probands with PNDM/ MDI, using sequential screening of KCNJ11, INS and ABCC8 genes in infants diagnosed within the first 6 months of age. This percentage decreased to $12 \%$ in those with diabetes diagnosed between 7 and 12 months. Patients belonging to the latter group may either carry mutations in genes different from those commonly found in PNDM/MDI or have developed an early-onset form of autoimmune diabetes.

Keywords $A B C C 8$ gene - Infancy-onset diabetes mellitus . INS gene $\cdot$ KCNJ11 gene - Monogenic diabetes of infancy . Neonatal diabetes mellitus $\cdot$ Non-syndromic diabetes

\begin{tabular}{|c|c|}
\hline \multicolumn{2}{|c|}{ Abbreviations } \\
\hline $\mathrm{CNV}$ & Copy number variation \\
\hline DEND & Developmental delay, epilepsy, neonatal diabetes \\
\hline GADA & Glutamic acid decarboxylase autoantibodies \\
\hline IA-2A & $\begin{array}{l}\text { Tyrosine phosphatase-related proteins islet anti- } \\
\text { gen } 2 \text { autoantibodies }\end{array}$ \\
\hline IAA & Insulin autoantibodies \\
\hline ICA & Islet-cell antibodies \\
\hline iDEND & Intermediate DEND \\
\hline IPEX & $\begin{array}{l}\text { Immune dysregulation, polyendocrinopathy, } \\
\text { enteropathy, X-linked }\end{array}$ \\
\hline ISPED & $\begin{array}{l}\text { Italian Society of Pediatric Endocrinology and } \\
\text { Diabetology }\end{array}$ \\
\hline $\mathrm{K}_{\mathrm{ATP}}$ & ATP-sensitive potassium channel \\
\hline MDI & Monogenic diabetes of infancy \\
\hline MLPA & Multiplex ligation-dependent probe amplification \\
\hline PNDM & Permanent neonatal diabetes mellitus \\
\hline TNDM & Transient neonatal diabetes mellitus \\
\hline ZnT8A & Zinc transporter 8 autoantibodies \\
\hline
\end{tabular}

M. Vanelli

Department of Pediatrics, University of Parma,

Parma, Italy

L. Aguilar-Bryan

Pacific Northwest Diabetes Research Institute,

Seattle, WA, USA

V. Grasso

Department of Laboratory Medicine,

Tor Vergata University Hospital,

Rome, Italy

F. Barbetti $(\triangle)$

Department of Internal Medicine, University of Tor Vergata,

Via Montpellier 1,

00134, Rome, Italy

e-mail: mody.2@libero.it

\section{Introduction}

Permanent diabetes with onset within the first 6 months following birth (permanent neonatal diabetes mellitus $[\mathrm{PNDM}] /$ monogenic diabetes of infancy $[\mathrm{MDI}]$ ) is a rare condition associated with defects in genes that play major roles in pancreatic beta cell development and function; mutations in the genes encoding the ATP-sensitive potassium channel $\left(\mathrm{K}_{\text {ATP }}\right)$ subunits, KCNJ11 (also known as KIR6.2), ABCC8 (also known as SUR1) and insulin (INS), account for most cases of PNDM/MDI [1-6]. Mutations in both the $\mathrm{K}_{\mathrm{ATP}}$ channel and INS genes can also cause diabetes with onset in childhood and adulthood [7-9]. In addition, $\mathrm{K}_{\mathrm{ATP}}$ channel mutations are a prominent cause of transient neonatal diabetes mellitus (TNDM), a form of neonatal/infancy-onset diabetes that usually remits within 6 months of its onset $[1,2,4]$. Mutations in $\mathrm{K}_{\mathrm{ATP}}$ channel genes that cause PNDM/MDI are usually activating, dominant and sporadic, but patients with recessive mutations in $A B C C 8$ have also been described [10]. Patients with INS gene mutations, which can be either dominant $[5,6]$ or recessive [11], present with nonsyndromic diabetes. In contrast, patients carrying mutations to $\mathrm{K}_{\text {ATP }}$ genes may also show variable degrees of motor/mental developmental delay with epilepsy (developmental delay, epilepsy, neonatal diabetes; DEND) or without epilepsy (intermediate DEND; iDEND). Moreover, individuals with some exceedingly rare forms of syndromic PNDM may bear recessive mutations in several genes, including $P D X 1$, EIF2AK3, PTF1A, GLIS3, RFX6 or FOXP3 [12-18], while recessive mutations in glucokinase give rise to isolated neonatal diabetes [19]. In 2002 we reported the basis for the currently used definition of PNDM/MDI by providing strong evidence that permanent diabetes with onset within 6 months of life is not autoimmune, but rather genetic, in origin [20]. This conclusion was supported by the absence of type 1 diabetes mellitus autoantibodies in patients presenting with diabetes in the first 180 days of life. In the present investigation we have assessed the power of this temporal cut-off in defining neonatal/ infancy-onset diabetes by performing sequential screening of $K C N J 11, I N S$ and $A B C C 8$ genes in 54 patients with permanent diabetes: 46 patients with onset of the disease within 6 months from birth, and eight patients between 7 months and 1 year of age. In those who were negative for mutations in the initial screening, five other candidate genes (ERN1, CHGA, CHGB, NKX6-1 and $C A C N A 1 C$ ) were sequenced. In specific patients, GCK, FOXP3, NEUROG3 and CDK4 genes and gene copy number variations were also evaluated.

\section{Methods}

Probands A total of 46 patients with diabetes onset before 6 months of age $(17$, or $37 \%$, with onset within the first 
6 weeks of life) (group 1) and eight patients with diabetes diagnosed between 7 and 12 months (group 2) were included in this study. Of these 54 patients, 22 patients in group 1 and two in group 2 have not been reported previously. Most probands studied in the present investigation were of Italian descent, except for one of Moroccan (nd-VI/1), one of Albanian (nd-MI/3), one of Chinese (nd$\mathrm{MO} / 3$ ) and one of Masai descent (nd-RM/6; Table 1). Family history disclosed consanguinity only in the Albanian family. In group 1, a male patient (deceased; nd-BR/1) presented with a phenotype resembling IPEX (immune dysregulation, polyendocrinopathy, enteropathy, X-linked) syndrome [18]. Two other infants had syndromic diabetes with a phenotype that was different from DEND/iDEND, or any other form caused by known genes [12-17]. One of these (group 1) suffered from episodes of liver insufficiency, with high ammonium and transaminase levels and low albumin, but with a mute liver biopsy; he also presented with anaemia that was successfully treated with erythropoietin (nd-NA/2). The other patient (group 2)

Table 1 Clinical and genetic features of patients with diabetes onset within the first year of life studied in the present investigation

\begin{tabular}{|c|c|c|c|c|c|}
\hline Patient & T1D autoantibodies tested & $\begin{array}{l}\text { Age at onset } \\
\text { (days) }\end{array}$ & Gene variant & Other features & SU treatment \\
\hline \multicolumn{6}{|l|}{ Group 1} \\
\hline nd-VI/1 & ICA, GADA, IA-2A & 1 & $K C N J 11 / \mathrm{V} 59 \mathrm{~A}$ & DEND & Yes \\
\hline nd-BR/1 & None & 2 & - & Diarrhoea & \\
\hline nd-RM/4 & IAA, GADA, IA-2A & 2 & $K C N J 11 / \mathrm{R} 201 \mathrm{~S}$ & & Yes \\
\hline nd-MI/3 & IAA, GADA, IA-2A, ZnT8A & 2 & $K C N J 11 / \mathrm{R} 201 \mathrm{C}$ & & Yes \\
\hline nd-PD/2 & None & 3 & $A B C C 8 / \mathrm{L} 213 \mathrm{P}$ & DEND & Yes \\
\hline nd-FI/1 & None & 15 & $\begin{array}{c}A B C C 8 / \mathrm{V} 324 \mathrm{M} ; \\
A B C C 8 / \mathrm{W} 688 \mathrm{R}\end{array}$ & & Yes \\
\hline nd-CT/2 & None & 27 & - & & \\
\hline nd-MI/2 & ICA, GADA, IA-2A & 38 & $K C N J 11 / \mathrm{K} 170 \mathrm{R}$ & & Yes \\
\hline nd-LE/2 & ICA, IAA, GADA, IA-2A & 39 & - & & \\
\hline nd-PR/2 & None & 40 & $A B C C 8 / \mathrm{L} 213 \mathrm{P}$ & iDEND & Yes \\
\hline nd-NA/1 & None & 40 & $K C N J 11 / \mathrm{R} 201 \mathrm{C}$ & & Yes + insulin \\
\hline nd-CT/1 & none & 60 & KCNJ11/V59M & iDEND & Yes \\
\hline nd-NA/2 & ICA, GADA, IA-2A & 71 & $A B C C 8 / \mathrm{A} 355 \mathrm{~T}$ & Anaemia & Yes + insulin \\
\hline nd-MO/3 & ICA, IAA, GADA & 73 & $K C N J 11 / \mathrm{H} 46 \mathrm{Y}$ & & Yes \\
\hline nd-RM/4 & IAA, GADA, IA-2A & 80 & - & & \\
\hline nd-TO/3 & GADA, IA-2A & 82 & - & & \\
\hline nd-TS/2 & None & 120 & KCNJ11/V59M & iDEND & Yes \\
\hline nd-RM/6 & None & 120 & $K C N J 11 / \mathrm{R} 195 \mathrm{H}^{\mathrm{a}}$ & & \\
\hline nd-RM/5 & IAA, GADA, IA-2A & 135 & KCNJ11/E322K & & Yes \\
\hline nd-PI/1 & ICA & 141 & - & & \\
\hline nd-BG/1 & GADA & 180 & $A B C C 8 / \mathrm{S} 1054 \mathrm{~N}^{\mathrm{a}}$ & & \\
\hline nd-CES/3 & None & 190 & - & & \\
\hline \multicolumn{6}{|l|}{ Group 2} \\
\hline $\mathrm{mdi}-\mathrm{RM} / 3$ & None & 220 & $K C N J 11 / \mathrm{V} 59 \mathrm{M}$ & iDEND & Yes \\
\hline mdi/NA-B/1 & ICA & 251 & - & & \\
\hline mdi-PA/1 & ICA, IAA, GADA, IA-2A & 270 & - & & \\
\hline mdi-RM-OBG/1 & IAA, GADA & 289 & - & Muscle hypotrophy & \\
\hline mdi-CES/1 & ICA, IAA & 300 & - & & \\
\hline mdi-RM-OBG/3 & IAA, GADA, IA-2A & 330 & - & & \\
\hline mdi-RM-OBG/2 & IAA, GADA, IA-2A & 330 & - & & \\
\hline mdi-NA/2 & GADA, IA-2A & 354 & - & & \\
\hline
\end{tabular}

SU treatment denotes complete withdrawal of insulin therapy unless specified. Mutations $K C N J 11 / \mathrm{H} 46 \mathrm{Y}$ and $K C N J 11 / \mathrm{V} 59 \mathrm{~A}$ were found in probands with Chinese and Moroccan ancestry, respectively. The Albanian patient carried mutation KCNJ11/R201C

T1D type 1 diabetes, SU sulfonylurea

${ }^{a}$ Benign gene variants 
showed muscle hypotrophy in the lower limbs, delayed puberty and retarded growth (mdi-RM-OBG/1).

Type 1 diabetes autoantibodies Twenty-seven patients in group 1 and all patients in group 2 tested negative for at least one type 1 diabetes autoantibody (i.e. ICA [islet cell autoantibodies], IAA [insulin autoantibodies], GADA [glutamic acid decarboxylase autoantibodies], IA-2A [tyrosine phosphatase-related proteins islet antigen 2 autoantibodies] or ZnT8A [zinc transporter 8 autoantibodies]) evaluated at the time of diagnosis.

Genetic testing Informed consent was obtained at each local paediatric diabetes centre involved in the study. Genomic DNA was extracted from peripheral lymphocytes by DNeasy Tissue Isolation kit (Qiagen, Valencia, CA, USA), amplified by PCR and sequenced using a DNA automated sequencer (Applied Biosystems ABI 3730, Foster City, CA, USA). Based on their frequency, our current routine for new cases is to sequence $K C N J 11$ and INS genes at the same time and, if no mutation is found, the larger $A B C C 8$ gene is examined $[4,6,21]$. In those patients where no mutation was identified, the entire coding region of the following candidate genes, ERN1, CHGA, CHGB, NKX6-1 (in patients in groups 1 and 2) and $C A C N A 1 C$ (in group 1 only), were sequenced. CACNA1C [22], which encodes voltagedependent L-type calcium channel subunit alpha-1C (CAV1.2), CHGA, CHGB [23] and ERN1 [24] were chosen for their role in insulin secretion; NKX6-1 was selected because of its role in endocrine pancreas development [25]. In particular, ERN1 encodes inositol-requiring protein 1 (IRE1A), which is involved in the unfolded protein response and insulin biosynthesis [24]. FOXP3 and NEUROG3 were sequenced in the proband with IPEX-like features [18, 26], $C D K 4$ in the proband with diabetes and muscle hypotrophy [27], and $G C K$ in patients presenting with diabetes onset in the first week of life, together with low birthweight [19]. Primer sequences and PCR conditions for candidate genes are listed in Table 1 of the electronic supplementary material (ESM).

New variants in $\mathrm{K}_{\text {ATP }}$ genes were searched by DNA direct sequencing of genomic DNA from 50 normal controls.

The multiplex ligation-dependent probe amplification (MLPA) technique (MRC-Holland, Amsterdam, the Netherlands) was applied to search for $A B C C 8$ gene deletions. In two patients with syndromic diabetes, copy number variations (CNVs) were also assessed. Patients' genomic DNA was analysed with the GeneChip 6.0 microarray (Affymetrix, Santa Clara, CA, USA). Labelled DNA was hybridised for 16-18 h; the chip was washed, stained and scanned using a Scanner 3000 7G (Affymetrix). The generated file, containing a single intensity value calculated for each probe, was loaded into Genotyping Console 3.0.2 and the SNP 6.0 copy number calls from 270 International HapMap Project control samples (www. hapmap.org/) were used as a reference model file for comparison. CNVs were selected based on variables previously described [28].

PNDM/MDI incidence in Italy Information was obtained from the Italian network database on early-onset diabetes (presentation within the first 24 months of life). The database works under the auspices of the Italian Society of Pediatric Endocrinology and Diabetology (ISPED) and collects clinical data from 45 paediatric diabetes clinics, which are the referral centres for the diagnosis and treatment of patients with neonatal and childhood diabetes in Italy.

Incidence rates per 100,000 live births were computed for cases that developed diabetes in the first 6 months of life and were born between 1995 and 2009. For comparison, we also calculated incidence rates utilising the old (1995) limit of $\leq 42$ days of life for the diagnosis of PNDM [29]. Confidence intervals for incidence rates were estimated using the exact Poisson distribution.

\section{Results}

Disease-causing mutations in $K_{A T P}$ genes In group 1, heterozygous mutations in the KCNJ11 gene were identified in 23 patients $(50 \%)$, including 14 probands previously reported by our group [21, 30-32]. All mutations were considered to be de novo, because parental DNA sequencing disclosed wild-type KCNJ11 genes. Table 1 shows mutations recently or previously identified in patients with PNDM/MDI, including H46Y (nd-MO/3) [33], V59A (ndVI/1) [34], V59M, K170R, R201C and E322K (nd-RM/25; Table 1) [35]. We also identified a new substitution, arginine by serine, in codon 201 (R201S, c.601C $>$ A), that we believe is novel (nd-RM/4). In Group 2, we found the previously described $K C N J 11 / \mathrm{V} 59 \mathrm{M}$ mutation $[3,21]$ in a patient with diabetes diagnosed at 220 days of life (mdi$\mathrm{RM} / 3$ ). $A B C C 8$ gene sequencing led to the identification of five heterozygous mutations in four probands from group 1 . $A B C C 8 / \mathrm{L} 213 \mathrm{P}$ (c.638T $>\mathrm{C}$ ) was found to be a de novo mutation in a patient with complete DEND syndrome (nd$\mathrm{PD} / 2$ ), and in a second proband with iDEND, who had inherited the mutation from her father (Fig. 1), who also presented with iDEND (nd-PR/2). A mutation in the same codon, $A B C C 8 / \mathrm{L} 213 \mathrm{R}$, has been previously reported in association with iDEND [36]. Of our patients, one proband was a compound heterozygote for the $A B C C 8 / \mathrm{V} 324 \mathrm{M}$ mutation, previously described in patients with the transient form of the disease (TNDM) [36], who usually need insulin therapy for less than 1 year [4], and for the novel W688R 
Family nd-FI/1
I.

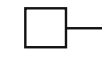

I.

III.

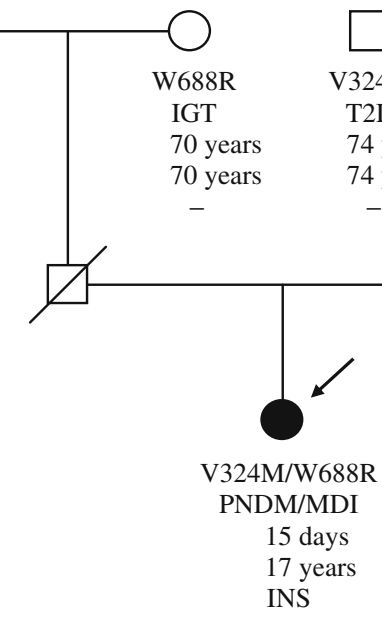

Family nd-NA/2

I.

II.

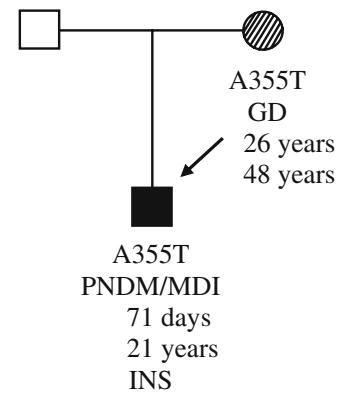

Family nd-PR/2

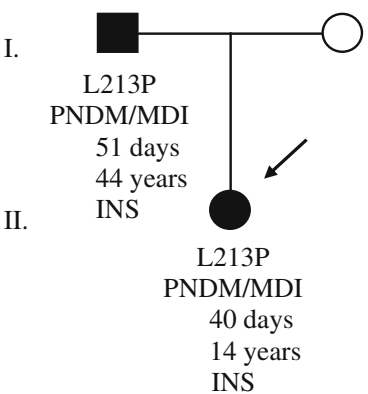

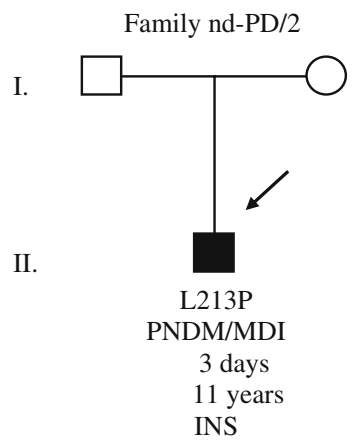

Fig. 1 Pedigrees of four families with mutations in $A B C C 8$; from top to bottom: mutation, phenotype, age at presentation/diagnosis of diabetes, current age and initial therapy for diabetes. For the two grandparents of proband nd-FI/1, OGTT tests were performed at 70 (W688R) and $74(\mathrm{~V} 324 \mathrm{M})$ years of age. GD, gestational diabetes; IGT, impaired glucose tolerance; INS, insulin

(c.2062T $>$ G) mutation (nd-FI/1). Residue W688 is conserved in dog, cow, mouse, chicken and zebra fish. Because both of the patient's parents were deceased, we analysed the grandparents' DNA and confirmed the $A B C C 8 / \mathrm{V} 324 \mathrm{M}$ mutation in the maternal grandfather and the $A B C C 8 /$ W688R mutation in the paternal grandmother (Fig. 1). After identifying the mutations, an OGTT was done in both patients; the carrier for V324M was diagnosed with diabetes ( $2 \mathrm{~h}$ plasma glucose $14 \mathrm{mmol} / \mathrm{l})$ and the carrier for W688R presented with impaired glucose tolerance $(2 \mathrm{~h}$ plasma glucose $8.4 \mathrm{mmol} / \mathrm{l})$. Finally, a patient carrying the unreported $A B C C 8 / \mathrm{A} 355 \mathrm{~T}$ (c.1063G $>\mathrm{A}$; nd-NA/2) variant inherited the mutation from his mother, who was diagnosed with gestational diabetes at the age of 26 years. Residue A355 is conserved in dog, cow, rat, mouse and chicken, but not in zebra fish, where it is substituted by glycine. None of the new KCNJ11 or $A B C C 8$ mutations was detected in 100 chromosomes from normal controls.

Polymorphisms $-K_{A T P}$ genes In the patient of Masai descent (nd-RM/6) we detected the variant KCNJ11/ R195H (c.584G $>A$; single nucleotide polymorphism: rs5217; Table 1), while in the proband nd-BG/1 we found the variant $A B C C 8 / \mathrm{S} 1054>\mathrm{N}$ (c. $3161 \mathrm{G}>\mathrm{A}$, numbered according to [36]; Table 1), inherited from the patient's father, who had normal glucose tolerance. MLPA of the $A B C C 8$ gene did not disclose any deletion in this patient. Thus, we currently classify $A B C C 8 / \mathrm{S} 1054 \mathrm{~N}$ as a rare, benign variant, taking into account the fact that residue S1054 is conserved from dog through to mouse, but not in chicken and zebra fish, where is substituted by cysteine and valine, respectively.

No additional mutations were found in INS (6), GCK (19) or any of the other genes (FOXP3, NEUROG3, ERN1, CHGA, CHGB, NKX6-1, CACNA1C and CDK4) screened at this time.

Clinical features in patients with diabetes and negative for KCNJ11, INS and ABCC8 Patients from group 1, negative in the genetic screening for genes commonly causing PNDM/MDI (hereafter called PNDM/MDI ' $X$ ') had a higher birthweight (median 3,164 g) than patients with KCNJ11 mutations (median $2,460 \mathrm{~g} ; p<0.0003$ ), and similar to individuals carrying INS mutations (Table 2). Moreover, in patients with PNDM/MDI ' $\mathrm{X}$ ', diabetes was diagnosed 1 month later (median) than carriers of mutations of $\mathrm{K}_{\text {ATP }}$ genes.

Incidence of $P N D M / M D I$ in Italy The incidence of PNDM/MDI was calculated at 1:210,287 (95\% CI 1:300,300-1:151,976) live births for years 1995-2009. Of note, 22 out of 23 patients (95\%) included in the database for years 2000-2009 (incidence rate: $1: 213,198,95 \%$ CI 1:336,700-1:142,045) have been subjected to genetic screening for KCNJ11, INS and $A B C C 8$ and $15(68 \%)$ carried a causative mutation in either KCNJ11 or INS. The incidence rate (years 19952009) was found to be $1: 473,146$ when calculated using the original definition of neonatal diabetes as insulinrequiring hyperglycaemia with onset within the first 6 weeks of life [29]. 
Table 2 Birthweight and age at diabetes onset of probands with KCNJ11, INS and ABCC8 mutations and of unknown genetic origin

\begin{tabular}{lllll}
\hline Gene & KCNJ11 & INS & ABCC8 & Unknown \\
\hline$n$ & 22 & 9 & 4 & 8 \\
Birthweight (g) & $2,460 \pm 394.34$ & $3,050 \pm 203.88^{\dagger}$ & $2,825 \pm 663.79$ & $3,150 \pm 204.57^{\ddagger}$ \\
Age at diagnosis (days) & $53 \pm 59.7$ & $86 \pm 45.6$ & $275 \pm 30.0$ & $82 \pm 68.9$ \\
\hline
\end{tabular}

Birthweight and age at diabetes onset are median values \pm SD

Birthweight was not available for one patient carrying a KCNJ11 mutation, and for a second patient born in Kenya (nd-RM/6). The patient with IPEXlike features (birthweight $990 \mathrm{~g}$, born at 22 weeks of gestation) was not included in the group of unknown genetic aetiology (PNDM/MDI 'X') $p$ value vs KCNJ11: ${ }^{\dagger} 0.009,{ }^{\star} 0.003$

\section{Discussion}

In 2002 we suggested that the cause of diabetes in patients with disease onset within 6 months of life might be genetic [20]. At that time only one gene, $G C K$ [19], was known to be linked with rare cases of insulin-deficient diabetes, while IPF1 (also known as $P D X 1$ ), EIF $2 A K 3$ and FOXP3 had been associated with early onset, syndromic diabetes [12, 13, 18]. More recently, mutations in the KCNJ11, ABCC8 and INS genes have been identified, which cause diabetes with onset in the first 6 months of life [3-6] and beyond [7-9, 37]. In the present study, we report the identification, by sequential sequencing of the three latter genes, of a disease-causing mutation in 36 probands with diabetes diagnosed before 6 months of age and in a single patient with diabetes onset after 6 months but before 1 year of age. In Group 1, novel mutations in $K C N J 11 / \mathrm{R} 201 \mathrm{~S}, A B C C 8 / \mathrm{L} 213 \mathrm{P}$ and $A B C C 8 /$ $\mathrm{W} 688 \mathrm{R}$ were identified. The latter was found in a patient who also carried the TNDM-causing $A B C C 8 / \mathrm{V} 324 \mathrm{M}$ mutation [36]. PNDM/MDI can result from recessive $A B C C 8$ mutations, usually one with a mild activating effect and the other with loss-of-function, which are observed in recessive hyperinsulinism [10]. In our case, however, we favour the hypothesis that both $A B C C 8 / \mathrm{V} 324 \mathrm{M}$ and $A B C C 8 / \mathrm{W} 688 \mathrm{R}$ are mildly activating, based on the fact that W688R is associated with impaired glucose tolerance in the paternal grandmother. In contrast, we cannot explain at this time the extremely different phenotypes we observed in the carriers of the mutation $A B C C 8 / \mathrm{A} 355 \mathrm{~T}$, who show either PNDM/MDI or gestational diabetes. Previously, phenotypic variability in $A B C C 8$ mutation carriers has been described in families in which the proband presents with TNDM and first-degree relatives carry the same mutation showing early-onset type 2 diabetes or even normal glucose tolerance [7, 38]. Because the patient with $A B C C 8 / \mathrm{A} 355 \mathrm{~T}$ also has a liver-related and haematologic phenotype, it is conceivable that he may carry a mutation in another locus that impacts on glucose metabolism. Functional studies are definitely needed to firmly establish the impact of $A B C C 8 / \mathrm{A} 355 \mathrm{~T}$ on insulin secretion.

In the present work, the mutation detection rate of KCNJ11, INS and $A B C C 8$ genes was $78.2 \%$ (36/46) for patients in group 1 and $12.5 \%(1 / 8)$ for patients in group 2. After sequencing the same three genes, Støy et al. [39] obtained comparable results, with a $63 \%$ and $6.6 \%$ detection rate in patients for permanent diabetes before or after 6 months of life, respectively. Our results from group 1 were not influenced by type 1 diabetes autoantibody status, which was unknown in $15(40 \%)$ patients who harboured a diseasecausing mutation [6, 21, 30-32] (Table 1).

Sequencing of KCNJ11, INS and $A B C C 8$ in patients from group 2 was justified by the fact that mutations in these genes have previously been detected in patients with diabetes onset in infancy, childhood and even adulthood [7-9, 37, 38 and F. Barbetti, unpublished observations], eliciting a negative result in $>85 \%$ of cases examined. Screening of candidate genes in these and other patients was also negative [present study; 40]. Consequently, the autoimmune or genetic aetiology for seven of the remaining patients in group 2 remains open. Four patients tested negative for IAA, which are found at an increased rate in individuals with diabetes onset before 5 years of age, and one of these four was negative for all autoantibodies commonly used as tools for the diagnosis of type 1 diabetes. However, the latter patient may still harbour autoantibodies against ZnT8A, which can be detected as a single autoantibody in patients with type 1 diabetes previously classified as autoantibody-negative on the basis of existing markers (i.e. IAA, GADA, IA-2A and ICA) $[9,41]$. Of note, one patient who was negative to GADA at diagnosis (and carrying $H L A-D R 3 / D R 4$ ) and was initially included in group 2 became weakly GADA positive during the study; this individual was therefore re-classified as having type 1 diabetes and was not investigated further. A limitation/weakness of our study is that the HLA status of most patients in group 2 was unknown, and type 1 diabetes autoantibodies were not thoroughly tested.

Conversely, we think that the nine patients in group 1 who had no disease-causing mutation identified, and possibly the patient carrying the $A B C C 8 / \mathrm{A} 355 \mathrm{~T}$ mutation, who showed clinical features not associated with mutations to $\mathrm{K}_{\mathrm{ATP}}$ channel genes, are likely to carry a mutation in a locus that has not, as yet, been found. Seven of these 
patients presented with non-syndromic diabetes and birthweight close to normal (Table 2) and were not good candidates for screening of any of the known genes giving rise to syndromic diabetes [12-17] or hyperglycaemia in the first week of life [42, 43]. We therefore sequenced genes that we considered to be candidates, based on the phenotypic consequences of their manipulation/ablation in mice [22-25], with no success. Because hundreds of genes can have an impact on pancreatic beta cell function [44] we believe that new approaches, such as whole exome/genome sequencing, should be used in the future for PNDM/MDI gene discovery $[45,46]$.

The incidence rate of PNDM/MDI in Italy, utilising the 6 month limit as a cut-off for diagnosis of neonatal/infancyonset diabetes, is about 1:210,000 live births. This result is comparable to recent reports from Slovakia, the UK, the Netherlands and Poland [47, 48], showing an incidence of PNDM/MDI of 1:215,417 [47] and 1:260,000 [48], respectively. In summary, a molecular genetic diagnosis can be reached in $\sim 75 \%$ of patients with diabetes onset $\leq 6$ months of age when KCNJ11, INS and ABCC8 genes are sequenced in populations with a low consanguinity rate. Moreover, because the status of type 1 diabetes autoimmunity was unknown in about $40 \%$ of patients in this group, we also conclude that knowledge of type 1 diabetes autoantibodies is not a prerequisite to proceeding to genetic screening, which we recommend for all patients with diabetes onset before 6 months of age. The incidence of PNDM/MDI varies, as expected, if different age cut-offs for disease onset are used as criteria for aetiological (genetic vs autoimmune) diagnosis.

Acknowledgements Part of this work has been supported by the Fondazione Roma grant 'Molecular mechanisms in the pathogenesis of type 2 diabetes mellitus and its cardiovascular complications' to F. Barbetti and by the Transnational European research grant on Rare Diseases (ERANET 09 RARE 005). Funding for L. Aguilar-Bryan is from the Thrasher Research Fund.

Duality of interest The authors declare that there is no duality of interest associated with this manuscript.

Open Access This article is distributed under the terms of the Creative Commons Attribution Noncommercial License which permits any noncommercial use, distribution, and reproduction in any medium, provided the original author(s) and source are credited.

\section{Appendix}

Members of the ISPED Diabetes Study Group are:

Alessandria: R. Lera; Ancona: V. Cherubini; Arezzo: A. R. Fifi; Bari, Giovanni XXIII Hospital: C. Torelli, E.
Frezza; Bari, University: L. Cavallo; Bologna: S. Zucchini; Bolzano: B. Pasquino, P. Kaufmann; Cagliari, Brotzu Hospital: P. Frongia; Cagliari, University: N. Zedda, C. Ripoli; Caltanissetta: A. La Loggia; Campobasso: M. Cicchetti; Catania: D. Lo Presti; Catanzaro: F. Citriniti; Cesena: M. Pocecco; Chieti: F Chiarelli, S. Tumini; Como: M. Del Donno; Cosenza: M. R. De Marco; Crotone: N. Lazzaro; Feltre (Belluno): A.Vergerio; Ferrara: P. Banin; Firenze: S. Toni, L. Lenzi; Genova: R. Lorini, G. D'Annunzio; Livorno: S. Lucchesi; Locri: F. Mammì; Lucca: C. Meossi; Mantova: F. Bontempi; Massa Carrara: D. Pardi; Matera: R. Taccardi; Messina: F. Lombardo; Milano: F. Meschi, R. Bonfanti; Modena: L. Iughetti; Napoli, Federico II: A. Franzese, P. Buono; Napoli, SUN: F. Prisco, D. Iafusco; Novara: F. Cadario; Nuoro: A. F. Milia; Olbia: L. Bellu, G. Piredda; Padova: C. M. Monciotti; Palermo: F. Cardella; Parma: M. Vanelli, G. Chiari; Pavia: V. Calcaterra; Perugia: G. De Giorgi; Pisa: G. Federico; Potenza: F. Citro; Rimini: A. Marsciani; Roma, Bambino Gesù Hospital: M. Cappa, C. Bizzarri; Roma, Sapienza University: N. Sulli; Roma, Tor Vergata University: F. Barbetti, M.L. Manca Bitti; San Giovanni Rotondo (Foggia): M. Delvecchio; SanremoImperia: M. Cotellessa; Sassari: A. M. Marinaro; Thiene (Vicenza): R. Pesavento; Torino: F. Cerutti, I. Rabbone; Tortona (Alessandria): F. Fontana; Trento: V. Cauvin, M. Bellizzi; Treviglio (Bergamo): L. Gargantini; Trieste: G. Tonini, E. Faleschini; Varese: A. Salvatoni; Vercelli: M. Trada; Verona: L. Pinelli; Viterbo: C. Araldi.

\section{References}

1. Aguilar-Bryan L, Bryan J (2008) Neonatal diabetes mellitus, Endocr Rev 29:265-291

2. Murphy R, Ellard S, Hattersley AT (2008) Clinical implications of a molecular genetic classification of monogenic $\beta$-cell diabetes. Nat Clin Pract Endocrinol Metab 4:200-213

3. Gloyn AL, Pearson ER, Antcliff JF et al (2004) Activating mutations in the gene encoding the ATP-sensitive potassium channel subunit Kir6.2 gene and permanent neonatal diabetes. N Engl J Med 350:1838-1849

4. Babenko AP, Polak M, Cave $\mathrm{H}$ et al (2006) Activating mutations in the $A B C C 8$ gene in neonatal diabetes mellitus. N Engl J Med 355:456-466

5. Støy J, Edghill EL, Flanagan SE et al (2007) Neonatal Diabetes International Collaborative Group. Insulin gene mutations as a cause of permanent neonatal diabetes. Proc Natl Acad Sci USA 104:15040-15044

6. Colombo C, Porzio O, Liu M et al (2008) Seven mutations in the human insulin gene linked to permanent neonatal/infancy-onset diabetes mellitus. J Clin Invest 118:2148-2156

7. Yorifuji T, Nagashima K, Kurokawa $K$ et al (2005) The C42R mutation in the Kir6.2 (KCNJ11) gene as a cause of transient neonatal diabetes, childhood diabetes, or later-onset, apparently type 2 diabetes mellitus. J Clin Endocrinol Metab 90:3174-3178 
8. Molven A, Ringdal M, Nordbø AM et al (2008) Mutations in the insulin gene can cause MODY and autoantibody-negative type 1 diabetes. Diabetes 57:1131-1135

9. Bonfanti R, Colombo C, Nocerino V et al (2009) Insulin gene mutations as cause of diabetes in children negative for five type 1 diabetes autoantibodies. Diab Care 32:123-125

10. Ellard S, Flanagan SE, Girard CA et al (2007) Permanent neonatal diabetes caused by dominant, recessive, or compound heterozygous SUR1 mutations with opposite functional effects. Am J Hum Genet 81:375-382

11. Garin I, Edghill EL, Akerman I et al (2010) Recessive mutations in the INS gene result in neonatal diabetes through reduced insulin biosynthesis. Proc Natl Acad Sci USA 107:3105-3110

12. Stoffers DA, Zinkin NT, Stanojevic V, Clarke WL, Habener JF (1997) Pancreatic agenesis attributable to a single nucleotide deletion in the human IPF1 gene coding sequence. Nat Genet $15: 106-110$

13. Delepine M, Nicolino M, Barrett T, Golamaully M, Lathrop GM, Julier C (2000) EIF2AK3, encoding translation initiation factor 2alpha kinase 3, is mutated in patients with Wolcott-Rallison syndrome. Nat Genet 25:406-409

14. Sellick GS, Barker KT, Stolte-Dijkstra I et al (2004) Mutations in PTF1A cause pancreatic and cerebellar agenesis. Nat Genet 36:1301-1305

15. Senee V, Chelala C, Duchatelet S et al (2006) Mutations in GLIS3 are responsible for a rare syndrome with neonatal diabetes mellitus and congenital hypothyroidism. Nat Genet 38:682-687

16. Smith SB, Qu HQ, Taleb N et al (2010) Rfx6 directs islet formation and insulin production in mice and humans. Nature 463:775-780

17. Senee V, Vattem KM, Delepine M et al (2004) Wolcott-Rallison syndrome: clinical, genetic, and functional study of EIF $2 A K 3$ mutations and suggestion of genetic heterogeneity. Diabetes 53:1876-1883

18. Bennett CL, Christie J, Ramsdell F et al (2001) The immune dysregulation, polyendocrinopathy, enteropathy, X-linked syndrome (IPEX) is caused by mutations of FOXP3. Nat Genet 27:20-21

19. Njolstad PR, Sovik O, Cuesta-Munoz A et al (2001) Neonatal diabetes mellitus due to complete glucokinase deficiency. N Engl J Med 344:1588-1592

20. Iafusco D, Stazi MA, Cotichini R et al (2002) Permanent diabetes mellitus in the first year of life. Diabetologia 45:798-804

21. Massa O, Iafusco D, D'Amato E (2005) KCNJ11 activating mutations in Italian patients with permanent neonatal diabetes. Hum Mutat 25:22-27

22. Sinnegger-Brauns MJ, Hetzenauer A, Huber IG et al (2004) Isoform-specific regulation of mood behavior and pancreatic beta cell and cardiovascular function by L-type $\mathrm{Ca}^{2+}$ channels. J Clin Invest 113:1430-1439

23. Obermüller S, Calegari F, King A et al (2010) Defective secretion of islet hormones in chromogranin-B deficient mice. PLoS ONE 5:e8936

24. Lipson KL, Fonseca SG, Ishigaki S et al (2006) Regulation of insulin biosynthesis in pancreatic beta cells by an endoplasmic reticulum-resident protein kinase IRE1. Cell Metab $4: 245-254$

25. Sander M, Sussel L, Conners J et al (2000) Homeobox gene $N k x 6.1$ lies downstream of $N k x 2.2$ in the major pathway of betacell formation in the pancreas. Development 127:5533-5540

26. Wang J, Cortina G, Wu SV et al (2006) Mutant neurogenin-3 in congenital malabsorptive diarrhea. N Engl J Med 335:270 280

27. Mettus RV, Rane SG (2003) Characterization of the abnormal pancreatic development, reduced growth and infertility in $C D K 4$ mutant mice. Oncogene 22:8413-8421
28. Bernardini L, Alesi V, Loddo S et al (2010) High-resolution SNP arrays in mental retardation diagnostics: how much do we gain? Eur J Hum Genet 18:178-185

29. von Mühlendahl KE, Herkenhoff H (1995) Long-term course of neonatal diabetes. N Engl J Med 333:704-708

30. Tonini G, Bizzarri C, Bonfanti R et al (2006) Sulphonylurea treatment outweighs insulin therapy in short-term metabolic control of patients with permanent neonatal diabetes mellitus due to activating mutations of the KCNJ11 gene. Diabetologia 49:2210-2213

31. Masia R, Koster JC, Tumini S et al (2007) An ATP-binding mutation (G334D) in KCNJ11 is associated with a sulfonylureainsensitive form of DEND (Developmental Delay, Epilepsy, and Neonatal Diabetes). Diabetes 56:328-336

32. Koster JC, Cadario F, Kurata HT et al (2008) The G53D mutation in Kir6.2 $(\mathrm{KCNJ} 11)$ is associated with neonatal diabetes and motor dysfunction in adulthood that is improved with sulfonylurea therapy. J Clin Endocrinol Metab 93:1054-1061

33. Flanagan SE, Edghill EL, Gloyn AL, Ellard S, Hattersley AT (2006) Mutations in KCNJ11, which encodes Kir6.2, are a common cause of diabetes diagnosed in the first months of life, with the phenotype determined by genotype. Diabetologia 49:1190-1197

34. Winkler M, Lutz R, Russ U, Quast U, Bryan J (2009) Analysis of two KCNJ11 neonatal diabetes mutations, V59G and V59A, and the analogous $K C N J 8$ I60G substitution: differences between the channel subtypes formed with SUR1. J Biol Chem 284:67526762

35. Vaxillaire M, Populaire C, Busiah K et al (2004) Kir6.2 mutations are a common cause of permanent neonatal diabetes in a large cohort of French patients. Diabetes 53:2719-2722

36. Flanagan SE, Clauin S, Bellané-Chantelot C et al (2009) Update of mutations in the genes encoding the pancreatic beta-cell KATP channel subunits Kir6.2 (KCNJ11) and sulfonylurea receptor 1 $(A B C C 8)$ in diabetes mellitus and hyperinsulinism. Hum Mutat 30:170-180

37. Boesgaard TW, Pruhova S, Andersson EA et al (2010) Further evidence that mutations in INS can be a rare cause of Maturity Onset Diabetes of the Young (MODY). BMC Med Genet 11:42

38. Flanagan SE, Patch A-M, Mackay DJG et al (2007) Mutations in ATP-sensitive $\mathrm{K}^{+}$channel genes cause transient neonatal diabetes and permanent diabetes in childhood or adulthood. Diabetes 56:1930-1937

39. Støy J, Greeley SA, Paz VP et al (2008) Diagnosis and treatment of neonatal diabetes: a United States experience. Pediatr Diabetes 9:450-459

40. Nocerino V, Colombo C, Bonfanti R, Iafusco D, Barbetti F (2009) Mutations in hIAPP and NEUROG3 genes are not a common cause of permanent neonatal/infancy/childhood onset diabetes. Diabet Med 26:660-661

41. Wenzlau JM, Moua O, Sarkar SA et al (2008) S1C30A8 is a major target of humoral autoimmunity in type 1 diabetes and a predictive marker in prediabetes. Ann NY Acad Sci 1150:256-259

42. Njolstad PR, Sagen JV, Bjorkhaug L et al (2003) Permanent neonatal diabetes caused by glucokinase deficiency: inborn error of the glucose-insulin signaling pathway. Diabetes $52: 2854-2860$

43. Nicolino M, Claiborn KC, Senée V et al (2010) A novel hypomorphc $P D X 1$ mutation responsible for permanent neonatal diabetes with subclinical exocrine deficiency. Diabetes 59:733740

44. Kutlu B, Burdick D, Baxter D et al (2009) Detailed transcriptome atlas of the pancreatic beta cell. BMC Med Genomics 2:3

45. Choi M, Scholl UI, Ji W et al (2009) Genetic diagnosis by whole exome capture and massively parallel DNA sequencing. Proc Nat Acad Sci USA 106:19096-19101 
46. Bonnefond A, Durand E, Sand O et al (2010) Molecular diagnosis of neonatal diabetes mellitus using next-generation sequencing of whole exome. PLoS ONE 5:e13630

47. Stanik J, Gasperikova D, Paskova M et al (2007) Prevalence of permanent neonatal diabetes in Slovakia and successful replacement of insulin with sulfonylurea therapy in KCNJ11 and $A B C C 8$ mutation carriers. J Clin Endocrinol Metab 92:1276-1282

48. Slingerland AS, Shields BM, Flanagan SE et al (2009) Referral rates for diagnostic testing support an incidence of permanent neonatal diabetes in three European countries of at least 1 in 260,000 live births. Diabetologia 52:1683-1685 